\title{
Student Perceptions of Methylphenidate Abuse at a Public Liberal Arts College
}

\author{
Quinton Babcock, BA; Tom Byrne, PhD
}

\begin{abstract}
With the ever-increasing diagnosis of attention deficit hyperactivity disorder, methylphenidate has become readily accessible in the college environment. Several properties of methylphenidate indicate abuse liability. A survey regarding the recreational use of methylphenidate was distributed to the student body at a public, liberal arts college. More than $16 \%$ of the students reported they had tried methylphenidate recreationally, and $12.7 \%$ reported they had taken the drug intranasally. Use of the drug was more common among traditional students than among nontraditional students. Among traditional-age students, reports of methylphenidate use were roughly equivalent to reports of cocaine and amphetamine use. Environmental conditions characteristic of college student life may influence the recreational use of the drug.
\end{abstract}

Key Words: abuse, attention deficit hyperactive disorder, college students, drugs, methylphenidate

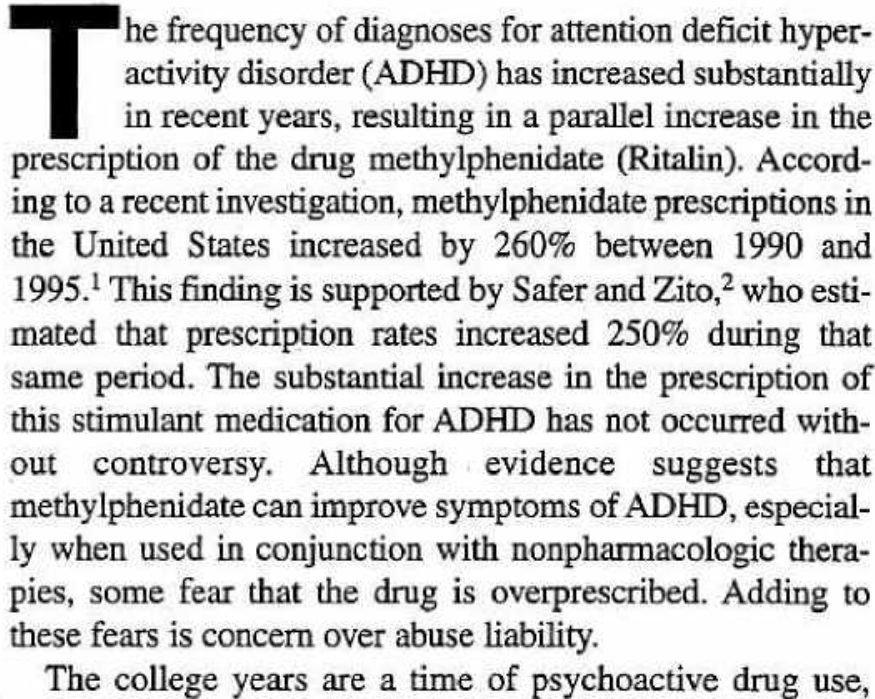

At the time this research was conducted, Quinton Babcock was a psychology student at Massachusetts College of Liberal Arts, North Adams, where Tom Byrne is an assistant professor in the Department of Psychology. and recreational use of stimulants is higher among 18- to 25-year-olds than in any other age group. ${ }^{3}$ College students diagnosed with $\mathrm{ADHD}$ not only fall within the age brackets most likely to abuse stimulants, they also present additional risk factors. Research indicates that rates of recreational drug use may be excessive among the ADHD population. ${ }^{4}$ Lambert and Hartsough ${ }^{5}$ found that persons with ADHD also had much higher rates of nicotine use.

Like cocaine and amphetamine, methylphenidate will maintain self-administration (manipulation of a switch or lever to produce a dose of drug) in laboratory animals. That methylphenidate will maintain self-administration is not surprising, considering its neuropharmacologic actions. Stimulants and most other drugs of abuse increase the activity of the neurotransmitter dopamine in the nucleus accumbens and the ventral tegmental area of the midbrain. It has been postulated that this system is crucially important for all types of reinforcement or rewarding experience. ${ }^{6,7}$ Stimulants affect this system directly: cocaine blocks the reuptake of dopamine, and amphetamine releases dopamine from presynaptic cells. ${ }^{8}$ In both cases, the net effect is an increase in dopaminergic activity. This activity is correlated with subjective states of pleasure. Methylphenidate increases dopaminergic activity in this reward pathway, ${ }^{9}$ just as cocaine and amphetamine do.

Curiously, scholarly examinations of methylphenidate abuse are rare in contrast to evaluations of its therapeutic benefits or lack of benefits, although many anecdotal reports exist. ${ }^{10-13}$ One exception, a survey by Musser et all, ${ }^{14}$ presents evidence that methylphenidate is a substance of abuse among school-age children. They found that $16 \%$ of the children surveyed reported having been approached to buy or sell Ritalin. Given the abuse potential of the drug, information regarding recreational use among the college population needs to be acquired and considered carefully in dealing with stimulant medication policies. We developed the survey described in 
this article to collect self-reports of the recreational use of methylphenidate in a college student population.

\section{METHOD}

The survey consisted of 10 yes-and-no questions designed to provide information regarding the recreational use of stimulants. The questions were designed for simplicity and for minimal response effort. We distributed the surveys to all enrolled students $(N=1401)$ at the Massachusetts College of Liberal Arts (MCLA), a public, 4-year college in North Adams, Massachusetts. Surveys, which were not addressed to individual students, were placed in all student mailboxes. Each survey included a cover letter explaining that the survey was confidential and that it was part of the first author's independent research requirements. The order and wording of the questions were identical to the listing shown in Table 1 . We provided no incentives for completing and returning the survey, and all completed surveys were returned to the first author through the campus mail system. These methods were approved by the MCLA Human Subjects Review Committee.

\section{RESULTS}

We included in the analysis all of the surveys we received within 30 days. Respondents (193 women, 88 men, 2 sex unreported) returned 283 surveys. The gender distribution was similar to campus population demographics ( 858 women and $550 \mathrm{men}$ ). Ages ranged from 18 to 51 years, with a median age of 21 years. Any questions that were left blank or were otherwise ambiguous were scored as "no." ( Table 1). Two questions asked respondents to report any self-administration of methylphenidate. More than $16 \%$ of the respondents reported trying methylphenidate recreationally, and $12.7 \%$ reported taking the drug intranasally. A majority of the respondents reported that they knew other students who used methylphenidate recreationally.

More than $20 \%$ of the returned surveys were completed by nontraditional students (persons aged 24 years and over). These nontraditional students make up $27 \%$ of the MCLA student population. Because nontraditional students typically do not live on campus and may be unaware of substance abuse trends, we analyzed the responses from traditional and nontraditional students separately.

In this analysis, we did not include survey responses in which age was not indicated. Nontraditional students were less likely to report using methylphenidate recreationally, and they were also less likely to report knowing other students who used the drug. In fact, no student over the age of 25 years reported using methylphenidate. However, nontraditional students were more likely to report having tried the traditional stimulants of abuse-cocaine and amphetamine. Among traditional-age students, reports of methylphenidate

\begin{tabular}{|c|c|c|c|}
\hline Question & $\begin{array}{l}\text { All students } \\
(n=283)\end{array}$ & $\begin{array}{l}\text { Age }<24 \text { y } \\
(n=214)\end{array}$ & $\begin{array}{c}\text { Age } \geq 24 \mathrm{y} \\
(n=67)\end{array}$ \\
\hline $\begin{array}{l}\text { Do you know any students at MCLA who } \\
\text { have ever taken Ritalin for fun (nonmedical } \\
\text { purposes)? }\end{array}$ & 53.4 & 65.4 & 17.9 \\
\hline $\begin{array}{l}\text { Have you ever taken Ritalin for fun (non- } \\
\text { medical purposes)? }\end{array}$ & 16.6 & 20.9 & 3.0 \\
\hline $\begin{array}{l}\text { Do you know any students at MCLA who } \\
\text { have ever snorted (nasally administered) } \\
\text { Ritalin? }\end{array}$ & 46.6 & 58.7 & 11.9 \\
\hline $\begin{array}{l}\text { Have you ever snorted (nasally administered) } \\
\text { Ritalin? }\end{array}$ & 12.7 & 16.1 & 1.5 \\
\hline Have you ever tried cocaine? & 21.9 & 16.1 & 38.8 \\
\hline Have you ever taken amphetamines? & 24.0 & 19.4 & 37.3 \\
\hline Have you ever stolen Ritalin? & 2.5 & 3.3 & 0 \\
\hline $\begin{array}{l}\text { Do you currently have a prescription for } \\
\text { Ritalin? }\end{array}$ & 1.8 & 1.9 & 1.5 \\
\hline $\begin{array}{l}\text { Do you know students at MCLA from whom } \\
\text { you can purchase Ritalin? }\end{array}$ & 35.7 & 45.5 & 7.4 \\
\hline $\begin{array}{l}\text { In your opinion, is Ritalin a drug of abuse on } \\
\text { this campus? }\end{array}$ & 31.4 & 36.0 & 16.4 \\
\hline
\end{tabular}


use were roughly equivalent to reports of cocaine and amphetamine use.

\section{COMMENT}

To our knowledge, this is the first survey of methylphenidate abuse in a college population. Because $16 \%$ of traditional-age respondents reported snorting the substance, it is clear that the recreational use of methylphenidate occurs on our campus. Intranasal administration provides a rapid distribution of molecules to sites of action, magnifying the drug's subjective effects.

Features common to many college environments may contribute to the recreational use of methylphenidate. Stimulants delay the need to sleep and have been used for this purpose legally and illicitly. Personal communications with students at MCLA suggest that methylphenidate is sometimes used as a study aid for "pulling all-nighters." Such use has also been reported in the media. ${ }^{15}$ This property of the drug may influence the likelihood of experimentation among the college population. Data from a recent study demonstrate that sleep depravation increases methylphenidate's efficacy as a reinforcer. Human volunteers were much more likely to administer methylphenidate than a placebo after they slept only 4 hours a night. On days when participants received 8 hours of sleep, they indicated they chose the placebo in preferences to methylphenidate. ${ }^{16} \mathrm{It}$ is not clear, however, whether using the drug to suppress sleep leads to abusive patterns of intake.

Recreational use of methylphenidate presents some health concerns. The abuse of any stimulant drug may be accompanied by harmful side effects. A large dose of methylphenidate may lead to extreme sympathomimetic effects and cardiac arrest. Such a reaction has caused the recorded death of at least one college student. ${ }^{15}$ The danger may be potentiated by intranasal administration, which causes the rapid delivery of methylphenidate molecules to sites of action in the central nervous system. It is also widely recognized that the recreational administration of stimulants can lead to chronic use and dependence.

We recognize a number of limitations to the current research. First, affirmative answers to the survey questions may indicate only one occurrence of recreational administration of stimulants. Therefore, the survey data do not provide any information about frequency or severity of use. Although data from the survey demonstrate that methylphenidate may be a drug of abuse among the college population, the patterns of use-whether chronic administration or simple experimentation-are not clear.

Although $20 \%$ of the student population returned a completed survey, those who chose to respond may not be representative of the college population. In addition, the validity of the instrument has not been tested. Therefore, the data cannot be considered an accurate representation of college student methylphenidate use. However, we believe the percentage of the student sample reporting nonmedical methylphenidate administration is noteworthy.

Recommendations based on the current data are clear.
- The abuse potential of methylphenidate must be taken seriously and factored into prescription decisions.

- Methylphenidate abuse may be an unfortunate risk of therapeutic practice.

- The abuse of stimulant medications must be viewed as a public health problem.

- Although methylphenidate is a scheduled substance, it would be unfortunate if society attempted to control use of the drug from a criminal justice viewpoint.

\section{NOTE}

For further information, please address correspondence to Tom Byrne, $\mathrm{PhD}$, Department of Psychology, Massachusetts College of Liberal Arts, 375 Church Street, North Adams, MA 01247 (e-mail: tbyme@mcla.mass.edu).

\section{REFERENCES}

1. Robinson LM, Sclar DA, Tracy L, Galin RS. National trends in the prevalence of attention-deficit/hyperactivity disorder and the prescribing of methylphenidate among school-age children: 1990-1995. Clin Pediatr. 1999;38:209-218.

2. Safer DJ, Zito JM. Increased methylphenidate usage for attention deficit disorder in the 1990s. Pediatrics. 1996;98: 1084-1089.

3. Preliminary Results From the 1997 National Household Survey on Drug Abuse. Rockville, MD: US Dept of Health and Human Services; 1998.

4. Lynskey MT, Ferguson DH. Childhood conduct problems, attention deficit behaviors and adolescent alcohol, tobacco and illicit drug use. J Abnorm Child Pyschol. 1995;23:281-302.

5. Lambert NM, Hartsough CS. Prospective study of tobacco smoking and substance dependence among samples of $\mathrm{ADHD}$ and non-ADHD participants. J Learn Disabil. 1998:533-545.

6. Koob GF. Drugs of abuse: Anatomy, pharmacology, and function of reward pathways. Trends Pharmacol Sci. 1992;13: 177-182.

7. Koob GF, Bloom FE. Cellular and molecular mechanisms of drug dependence. Science. 1988;242:715-723. 1998.

8. Julien RM. A Primer of Drug Action. New York: Freeman;

9. Volkow ND, Ding Y-S, Fowler JS, et al. Is methylphenidate like cocaine? Studies on their pharmacokinetics and distribution in human brain. Arch Gen Psychiatry. 1995;52:456-463.

10. Brierck R. Rx for abuse. US News \& World Report. 1998; 124:12.

11. Stecyk O, Loludice TA, Demeter S, Jacobs J. Multiple organ failure resulting from intraveneous abuse of methylphenidate hydrochloride. Ann Emerg Med. 1985;14:597-599.

12. Sherman CB, Hudson LD, Pierson DJ. Severe precocious emphysema in intravenous methylphenidate abusers. Chest. 1987;92:1085-1087.

13. Spensley J, Rockwell D. Psychosis during methylphenidate abuse. $N$ Engl J Med. 1972;266:880-881.

14. Musser CJ, Ahmann PA, Theye FW, Mundt P, Broste SK, Mueller-Rizner N. Stimulant use and the potential for abuse in Wisconsin as reported by school administrators and longitudinally followed children. Developmental Behavior Pediatrics. 1998;19: 187-192.

15. LaMotte L. Ritalin. The smart pill? CNN/Time Impact, 1997. Available: http://www.cnn.comVcnn/programs/impact/ 9705/04/feature/index.htm (5/99).

16. Roehrs T, Papineau K, Rosenthal L, Roth T. Sleepiness and the reinforcing and subjective effects of methylphenidate. Exp Clin Psychopharmacol. 1999;7:145-150. 